\title{
On the design of global refunding and climate change
}

\section{Working Paper}

Author(s):

Gersbach, Hans; Winkler, Ralph

Publication date:

2007-06

Permanent link:

https://doi.org/10.3929/ethz-a-005390621

Rights / license:

In Copyright - Non-Commercial Use Permitted

Originally published in:

Economics Working Paper Series 07/69 


\section{CER-ETH - Center of Economic Research at ETH Zurich}

\section{On the Design of Global Refunding and Climate Change}

Hans Gersbach and Ralph Winkler

Working Paper 07/69

June 2007

\section{Economics Working Paper Series}

\section{EH}

Eidgenössische Technische Hochschule Zürich Swiss Federal Institute of Technology Zurich 


\title{
On the Design of Global Refunding and Climate Change*
}

\author{
Hans Gersbach \\ CER-ETH - Center of Economic \\ Research at ETH Zurich and CEPR \\ Zürichbergstrasse 18 \\ 8032 Zurich, Switzerland \\ hgersbach@ethz.ch
}

\author{
Ralph Winkler \\ CER-ETH - Center of Economic \\ Research at ETH Zurich \\ Zürichbergstrasse 18 \\ 8032 Zurich, Switzerland \\ rtwinkler@ethz.ch
}

First Version: January 2007

This Version: June 2007

\begin{abstract}
We design a global refunding scheme as a new international approach to address climate change. A global refunding system allows each country to set its carbon emission tax, while aggregate tax revenues are partially refunded to member countries in proportion to the relative emission reductions they achieve within a given period, compared to some given baseline emissions. In a simple model we show that a suitably designed global refunding scheme is self-enforcing and achieves the social global optimum.
\end{abstract}

Keywords: climate change mitigation, global refunding scheme, international agreements, self-enforcing mechanisms

JEL: H23, Q54, H41

\footnotetext{
*We would like to thank the participants of the workshop "Environmental and Resource Economics" at ETH Zurich (25-27 Feb 2007) for valuable comments on an earlier draft. We are also grateful to Denys Dhiver for research assistance and to Andrew Jenkins for correcting our English.
} 


\section{Introduction}

The threat posed by climate change to the well-being of future generations appears to be substantial (see, e.g., Goulder and Pizer forthcoming, Stern 2006, Nordhaus 2006, Tol 2006). Mitigating climate change, however, is a global public good, as each country's efforts to control emissions will benefit all countries in a non-exclusive and non-rival manner. Countries therefore have an incentive to free-ride on other countries' efforts to reduce greenhouse gas emissions. The prisoner's dilemma aspect of mitigating climate change and the absence of a supranational authority makes international coordination both crucial and exceptionally difficult to achieve. Countries may either lack the incentive to sign an agreement and benefit from the signatories' abatement efforts or they may have incentives not to comply with promises made in an agreement.

There is a large body of literature addressing the underprovision of international pollution control. At the practical level the Kyoto Protocol, as the first significant international effort to reduce greenhouse gas emissions, has been criticized for being ineffective (see, e.g., Böhringer and Vogt 2003, Nordhaus and Boyer 1999, Schelling 2002, McKibbin and Wilcoxen 2002, Barrett 2003). As a consequence, various other approaches to international coordination have been suggested. Aldy et al. (2003) summarize the alternatives, which include an international carbon tax and international technology standards. Recently, Gersbach (2007) has proposed a further alternative for an international agreement by allowing each country to determine its own emission tax while aggregate tax revenues are partially refunded to members in proportion to the relative emission reductions they achieve within a given period. In this paper we design such a global refunding scheme and explore its potential for mitigating climate change.

A considerable body of research has examined the formation of international environmental agreements using game-theoretic models. The main focus of this literature is on the conditions leading to coalition formation by signing a multilateral agreement. Such agreements must be self-enforcing since there is no supranational authority to ensure compliance. Two types of models have been used: two-stage games (Carraro 2000, Carraro and Siniscalco 1993, 1998, Chander and Tulkens 1992, Finus et al. 2006, Hoel 1992) and infinitely repeated games (Asheim et al. 2006, Barrett 1994, 1999, 2003). The former approach has emphasized that either stable coalitions are small or that the abatement level that can be sustained in larger coalitions is small. The latter approach focuses on renegotiation proof agreements and shows that the allocation of abatement 
burdens is crucial for the formation of agreements. As in the two-stage game frameworks, it is unlikely that a grand coalition will be formed, and if it is formed it will achieve very little. Moreover, sub-coalitions may be better for their members than the grand coalition, and regional agreements can Pareto-dominate a regime based on a global treaty. A further strand of the literature employs cooperative game theory and applies transfer schemes to treaty-making (see Carraro et al. 2006 for a discussion of this literature and for the design of optimal transfer systems).

In general, an international agreement has to solve two problems: accession and selfenforcement. An international agreement will solve the accession problem if all countries voluntarily decide to join the treaty instead of free-riding. Self-enforcement means that it is in the interests of all countries to comply with the treaty over its whole lifetime. In this paper we concentrate on the problem of self-enforcement. Accordingly, we outline the mechanics of a global refunding scheme (GRS) and examine its potential for an international treaty. We consider a simple two-stage model in which each country can freely set national abatement levels by choosing a national tax rate. Participation implies an initial payment and that national abatement taxes are collected in a global fund, which is partially reimbursed in each period to member countries. Each country receives refunds in proportion to its relative emission reductions over the last period. The fraction of the fund that is not distributed to member countries is invested and earns profits. This creates a growing incentive for member countries to abate and to stay in the GRS.

We show that a suitably designed GRS is self-enforcing in the sense that compliance with abatement objectives is in the interests of all countries. In fact, provided that all countries join the GRS, it can induce countries to choose abatement levels that are globally optimal.

The paper is organized as follows: In Section 2 we introduce a simple two-period model with $n$ identical countries that can abate emissions by setting individual emission taxes. Net emissions accumulate to an aggregate stock that imposes a negative externality on all countries. In Section 3 we derive the socially optimal and decentralized solutions, which are the benchmarks for the analysis of the global refunding scheme introduced in Section 4. Here we discuss the properties of the global refunding scheme and show that, provided that all countries join, the GRS is self-enforcing and achieves the global optimum. In Section 5 we discuss the accession problem and some institutional and 
structural assumptions of our model. Section 6 concludes.

\section{The Model}

We consider a world lasting for two periods, $t=1$ and $t=2$. There are $n$ identical countries characterized by an emission function $E$, a cost function $C$, and a damage function $D$. Throughout the paper countries are indexed by $i$ and $j$.

Emissions of country $i$ in period $t$ are assumed to be a strictly decreasing linear function of emission taxes $\tau_{t}^{i}$. No emission tax results in baseline emissions $\bar{e}$ :

$$
E=E\left(\tau_{t}^{i}\right)=\bar{e}-\eta \tau_{t}^{i}, \quad \text { with } \quad \eta>0, \quad i=1, \ldots, n, \quad t=1,2
$$

We further assume that positive emission taxes $\tau^{i}$ in country $i$ (and hence positive emission reductions compared to the baseline emissions) induce strictly increasing and convex abatement costs: ${ }^{1}$

$$
C=C\left(\tau_{t}^{i}\right)=\frac{\phi}{2}\left(\tau_{t}^{i}\right)^{2}, \quad \text { with } \quad \phi>0, \quad i=1, \ldots, n, \quad t=1,2 .
$$

In period $t$ global emissions, which are the sum of the emissions of all countries, accumulate the stock of greenhouse gases, $s_{t}$, according to the following equation of motion:

$$
s_{t}=(1-\gamma) s_{t-1}+\sum_{i=1}^{n} E\left(\tau_{t}^{i}\right), \quad \text { with } \quad \gamma>0, \quad t=1,2,
$$

where $\gamma$ denotes the constant and positive natural decay rate of greenhouse gases in the atmosphere. ${ }^{2}$ The initial stock of greenhouse gases is denoted by $s_{0}$. Without loss of generality we assume that $s_{0}=0$. This simplifies further calculations without impacting qualitatively on our results.

The global stock of greenhouse gases in period $t, s_{t}$, gives rise to strictly increasing and strictly convex damage for each country $i$ :

$$
D=D\left(s_{t}\right)=\frac{\beta}{2} s_{t}^{2}, \quad \text { with } \quad \beta>0, \quad t=1,2 .
$$

Finally, countries are assumed to discount outcomes in period $t=2$ with the discount factor $\delta<1$.

\footnotetext{
${ }^{1}$ This is a standard short cut to capture aggregate abatement costs in country $i$ (see, e.g., Falk and Mendelsohn 1993).

${ }^{2}$ Note that emissions accumulate the stock of greenhouse gases instantaneously. This is a useful assumption in allowing for a two-period model.
} 


\section{Social Optimum and Decentralization}

Before we introduce the global refunding scheme (GRS) in the next section, we characterize the global social optimum and the decentralized solution when no international agreement has been reached. As is well known, the latter is inefficient because the emissions of each individual country induce negative externalities on all other countries that an individual country does not take into account when choosing its emission tax.

Both the global social optimum and the decentralized outcome are important benchmarks for any potential international agreement. Obviously, any agreement has to outperform the decentralized outcome in order to be seriously considered. Moreover, an agreement is "better", the closer its outcome is to the global social optimum.

\subsection{Global Social Optimum}

Consider a global social planner seeking to maximize global welfare, i.e., seeking to minimize the net present value of the global costs of emission abatement and the sum of national damages stemming from greenhouse gas emissions. The social planner's problem is given as:

$$
\min _{\left\{\tau_{1}^{i}\right\}_{i=1}^{n},\left\{\tau_{2}^{i}\right\}_{i=1}^{n}} \sum_{t=1}^{2} \delta^{t-1}\left[\sum_{j=1}^{n} \frac{\phi}{2}\left(\tau_{t}^{j}\right)^{2}+n \frac{\beta}{2} s_{t}^{2}\right],
$$

subject to equations (3), (1), and $\tau_{t}^{i} \geq 0, i=1, \ldots, n, t=1,2$.

We insert equation (1) into equation (3) and obtain the corresponding Lagrangian:

$$
\mathcal{L}=\sum_{t=1}^{2}\left\{\delta^{t-1}\left[\sum_{j=1}^{n} \frac{\phi}{2}\left(\tau_{t}^{j}\right)^{2}+n \frac{\beta}{2} s_{t}^{2}\right]+\lambda_{t}^{G O}\left[(1-\gamma) s_{t-1}+\sum_{j=1}^{n}\left(\bar{e}-\eta \tau_{t}^{j}\right)-s_{t}\right]\right\}
$$

where $\lambda_{t}^{G O}$ denotes the Langrange multiplier or shadow price for the global stock of greenhouse gases in period $t$. The first-order conditions for an optimal solution are

$$
\begin{aligned}
& \frac{\partial \mathcal{L}}{\partial \tau_{t}^{i}}=\phi \tau_{t}^{i} \delta^{t-1}-\eta \lambda_{t}^{G O}=0, \quad i=1, \ldots, n, t=1,2, \\
& \frac{\partial \mathcal{L}}{\partial s_{t}}=n \beta s_{t} \delta^{t-1}+(1-\gamma) \lambda_{t+1}^{G O}-\lambda_{t}^{G O}=0, \quad t=1,2,
\end{aligned}
$$

where $\lambda_{3}^{G O}=0$. Due to the strict convexity of the Lagrangian these necessary conditions are also sufficient for a unique solution. Equation (7b) can be solved by backward 
induction to yield

$$
\lambda_{t}^{G O}=n \beta \sum_{k=t}^{2} \delta^{k-1}(1-\gamma)^{k-t} s_{k}, \quad t=1,2 .
$$

Note that $\lambda_{t}^{G O}$ equals the net present value of all global future damages stemming from a marginal unit of emissions in period $t$. This makes the interpretation of equation (7a) straightforward. In the optimum, the costs incurred by a marginal increase of the emission tax $\tau_{t}^{i}$ equal the net present value of all future global damages prevented by the abatement of emissions via the marginal increase of the emission tax.

Inserting equation (8) into equation (7a) yields the $2 n$ necessary and sufficient conditions for the $2 n$ emission taxes $\tau_{t}^{i}$ for a global social optimum:

$$
\phi \tau_{t}^{i}=n \eta \beta \sum_{k=t}^{2}[\delta(1-\gamma)]^{k-t} s_{k}, \quad i=1, \ldots, n, t=1,2 .
$$

For given $t$, the right hand side of equation (9) is identical for all $i=1, \ldots, n$. As a consequence, all countries set the same emission taxes $\tau_{t}$ in the global social optimum. These are given by the following proposition:

\section{Proposition 1 (Global social optimum)}

Given the optimization problem (5) subject to equation (3), equation (1), $\tau_{t}^{i} \geq 0, \quad(i=$ $1, \ldots, n ; t=1,2)$, the optimal emission taxes $\tau_{t}^{\star}$ for all countries equal

$$
\begin{aligned}
\tau_{1}^{\star} & =n^{2} \eta \beta \bar{e} \frac{\phi[1+\delta(1-\gamma)(2-\gamma)]+n^{2} \eta^{2} \beta}{\left(\phi+n^{2} \eta^{2} \beta\right)^{2}+\phi n^{2} \eta^{2} \beta \delta(1-\gamma)^{2}}, \\
\tau_{2}^{\star} & =n^{2} \eta \beta \bar{e} \frac{\phi(2-\gamma)+n^{2} \eta^{2} \beta}{\left(\phi+n^{2} \eta^{2} \beta\right)^{2}+\phi n^{2} \eta^{2} \beta \delta(1-\gamma)^{2}} .
\end{aligned}
$$

This yields the following optimal stocks $s_{1}^{\star}$ and $s_{2}^{\star}$ :

$$
\begin{aligned}
& s_{1}^{\star}=n \phi \bar{e} \frac{\phi+n^{2} \eta^{2} \beta[1-\delta(1-\gamma)]}{\left(\phi+n^{2} \eta^{2} \beta\right)^{2}+\phi n^{2} \eta^{2} \beta \delta(1-\gamma)^{2}}, \\
& s_{2}^{\star}=n \phi \bar{e} \frac{\phi(2-\gamma)+n^{2} \eta^{2} \beta}{\left(\phi+n^{2} \eta^{2} \beta\right)^{2}+\phi n^{2} \eta^{2} \beta \delta(1-\gamma)^{2}} .
\end{aligned}
$$

The proof of Proposition 1 is given in the appendix.

\subsection{Decentralized Solution}

Next we examine a decentralized system where a local planner in each country (e.g. a government) seeks to minimize local costs and damages. We look for subgame perfect 
Nash equilibria when each country chooses its own sequence of emission taxes. Thus the optimization problem for country $i$ is given as follows:

$$
\min _{\tau_{1}^{i}, \tau_{2}^{i}} \sum_{t=1}^{2} \delta^{t-1}\left[\frac{\phi}{2}\left(\tau_{t}^{i}\right)^{2}+\frac{\beta}{2} s_{t}^{2}\right]
$$

subject to equations (3), (1), and $\tau_{t}^{i} \geq 0, t=1,2$.

Thus the corresponding Lagrangian yields

$$
\mathcal{L}=\sum_{t=1}^{2}\left\{\delta^{t-1}\left[\frac{\phi}{2}\left(\tau_{t}^{i}\right)^{2}+\frac{\beta}{2} s_{t}^{2}\right]+\lambda_{t}^{D S}\left[(1-\gamma) s_{t-1}+\sum_{j=1}^{n}\left(\bar{e}-\eta \tau_{t}^{j}\right)-s_{t}\right]\right\} .
$$

Again, $\lambda_{t}^{D S}$ denotes the Lagrange multiplier or shadow price of the stock of greenhouse gases in period $t$. Hence we derive the following necessary conditions:

$$
\begin{aligned}
& \frac{\partial \mathcal{L}}{\partial \tau_{t}^{i}}=\phi \tau_{t}^{i} \delta^{t-1}-\eta \lambda_{t}^{D S}=0, \quad t=1,2, \\
& \frac{\partial \mathcal{L}}{\partial s_{t}}=\beta s_{t} \delta^{t-1}+(1-\gamma) \lambda_{t+1}^{D S}-\lambda_{t}^{D S}=0, \quad t=1,2
\end{aligned}
$$

with $\lambda_{3}^{D S}=0$. Analogously to Section 3.1, these necessary conditions are also sufficient for a unique solution due to the strict convexity of the Lagrangian. By backward induction we obtain the following formula for the shadow price $\lambda_{t}^{D S}$ :

$$
\lambda_{t}^{D S}=\beta \sum_{k=t}^{2} \delta^{k-1}(1-\gamma)^{k-t} s_{k}, \quad t=1,2
$$

Inserting equation (15) into equation (14a) yields the 2 necessary and sufficient conditions for the emission taxes $\tau_{t}^{i}$ for a local optimum of country $i$, given the emission taxes $\tau_{t}^{j}$ of all other countries:

$$
\phi \tau_{t}^{i}=\eta \beta \sum_{k=t}^{2}[\delta(1-\gamma)]^{k-t} s_{k}, \quad t=1,2 .
$$

The set of the necessary and sufficient conditions (16) for all countries $i$, i.e., the set of emission taxes chosen by all countries in both periods, determines the subgame perfect equilibrium. Again, the right hand side is identical for all countries $i$ and the conditions are linear. As a consequence, all countries set the same equilibrium emission taxes $\hat{\tau}_{t}$ in $t=2$ and, by working backwards, also in $t=1$, as the following proposition states: 


\section{Proposition 2 (Decentralized solution)}

The dynamic game in which each country optimizes (12) subject to equation (3), equation (1), $\tau_{t}^{i} \geq 0(t=1,2)$, and given the behavior of all other countries, has a unique symmetric subgame perfect equilibrium, which is given by the following equilibrium emission taxes $\hat{\tau}_{t}$ :

$$
\begin{aligned}
& \hat{\tau}_{1}=n \eta \beta \bar{e} \frac{\phi[1+\delta(1-\gamma)(2-\gamma)]+n \eta^{2} \beta}{\left(\phi+n \eta^{2} \beta\right)^{2}+\phi n \eta^{2} \beta \delta(1-\gamma)^{2}} \\
& \hat{\tau}_{2}=n \eta \beta \bar{e} \frac{\phi(2-\gamma)+n \eta^{2} \beta}{\left(\phi+n \eta^{2} \beta\right)^{2}+\phi n \eta^{2} \beta \delta(1-\gamma)^{2}} .
\end{aligned}
$$

This yields the following equilibrium stocks $\hat{s}_{1}$ and $\hat{s}_{2}$ :

$$
\begin{aligned}
& \hat{s}_{1}=n \phi \bar{e} \frac{\phi+n \eta^{2} \beta[1-\delta(1-\gamma)]}{\left(\phi+n \eta^{2} \beta\right)^{2}+\phi n \eta^{2} \beta \delta(1-\gamma)^{2}}, \\
& \hat{s}_{2}=n \phi \bar{e} \frac{\phi(2-\gamma)+n \eta^{2} \beta}{\left(\phi+n \eta^{2} \beta\right)^{2}+\phi n \eta^{2} \beta \delta(1-\gamma)^{2}} .
\end{aligned}
$$

The proof of Proposition 2 is given in the appendix.

From equation (15) we see that in the decentralized outcome the shadow price for the stock of greenhouse gases, $\lambda_{t}^{D S}$, only accounts for local damages. In fact, abating emissions in country $i$ induces a positive externality for all other countries $j \neq i$ both now and in the future, as it reduces the global stock of greenhouse gases and hence the damages in all countries. In the subgame perfect equilibrium, these positive externalities are not taken into account. As a consequence, the shadow prices in the decentralized solution are lower than in the global social optimum. Accordingly, the optimal level of abatement (or emission tax) is higher and the optimal stocks of greenhouse gases are lower in the global social optimum. ${ }^{3}$

\section{Global Refunding Scheme}

We now design a global refunding scheme (GRS). Members are free to choose national emission taxes $\tau_{t}^{i}$ but agree to pay an initial fee $f_{0}^{i}$ into a global fund. In addition, the emission tax revenues of all countries in all periods are also collected in this fund. In

\footnotetext{
${ }^{3}$ This result is well known from public economics. The public good "emission reductions" is provided to a suboptimal degree because the producer (country $i$ ) is not sufficiently compensated by the consumers (countries $i \neq j$ ) of the public good.
} 


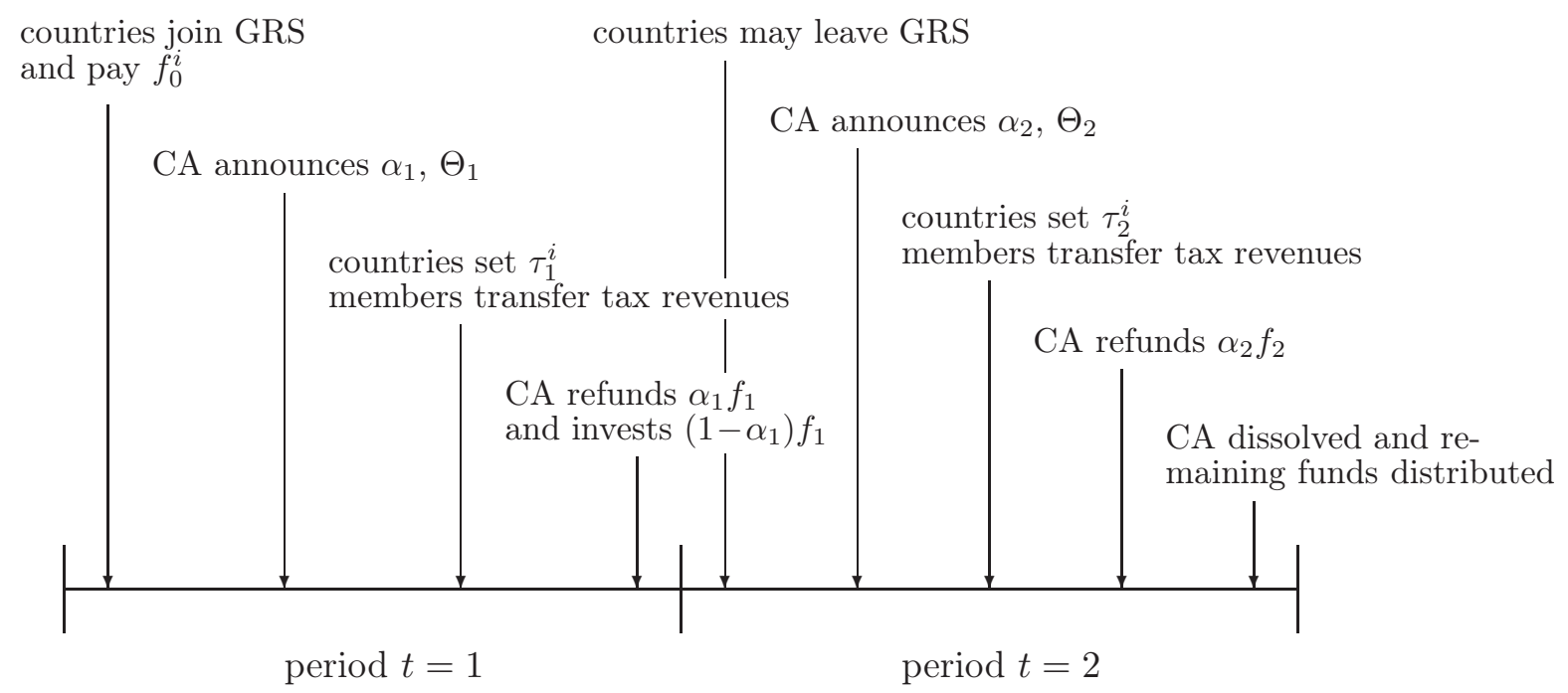

Figure 1: An illustration of the timing of the global refunding scheme.

each period $t$, a fraction $\left(1-\alpha_{t}\right)$ of the fund's assets is invested and earns interest $\rho$ per period. The remaining fraction $\alpha_{t}$ is reimbursed to the participating countries in proportion to the emission reductions they have achieved in this period.

In the following, we analyze the capacity of such a GRS to solve the free-riding incentives in the provision of the global public good of mitigating climate change. First we explain the rules and the timing of payments and refunds in detail and derive the optimal tax levels for member countries of the GRS. Second, given that all countries signing the treaty remain in the GRS over its whole lifetime, we show that the GRS can internalize the externalities induced within the member countries. Third, we show that the GRS is self-enforcing in the sense that all countries that have signed the agreement in the first period will also comply with the GRS in the second period. Thus, given that all countries join the GRS, the globally optimal level of emission abatement can be achieved.

\subsection{Rules and timing of the GRS}

The timing of the GRS is illustrated in Figure 1. At the beginning of period $t=1$ countries decide whether to sign the GRS or not. Signing the agreement requires the payment of an initial fee $f_{0}^{i}$, which is transferred to a global fund $f_{1}$. Participating countries set up a central agency (CA) that handles the global refunding scheme. The CA has the right to set the fractions $\alpha_{1}$ and $\alpha_{2}$ of the funds reimbursed to the member 
countries in periods $t=1$ and $t=2$, and the baseline emissions $\Theta_{1}$ and $\Theta_{2}$, which have to be undercut by member countries to be eligible for refunds. We assume that the $\mathrm{CA}$ acts in the interests of member countries. ${ }^{4}$ That is, the CA seeks to set the GRS parameters $f_{0}^{i}, \alpha_{t}$, and $\Theta_{t}$ to induce member countries to choose emission taxes internalizing the externalities imposed on other member countries. In formal terms, given the emission taxes of all non-participating countries, the CA seeks to achieve emission taxes among member countries that provide a solution to the optimization problem

$$
\min _{\left\{\tau_{1}^{i}\right\}_{i \in G R S},\left\{\tau_{2}^{i}\right\}_{i \in G R S}} \sum_{t=1}^{2} \delta^{t-1}\left\{\sum_{j \in G R S}\left[\frac{\phi}{2}\left(\tau_{t}^{j}\right)^{2}+\frac{\beta}{2} s_{t}^{2}\right]\right\},
$$

subject to equations (3), (1), and $\tau_{t}^{i} \geq 0, i \in G R S, t=1,2$.

The notation $i \in G R S(i \notin G R S)$ describes the membership status of country $i$ regarding the GRS. Assuming that $m_{1} \leq n$ countries join the GRS in period $t=1$ and $m_{2} \leq m_{1}$ countries stay in the GRS in period $t=2$, the emission taxes among member countries that the CA seeks to implement are given by the following proposition:

\section{Proposition 3 (Tax goal for GRS members)}

Suppose that $m_{1}$ countries $\left(i=1, \ldots, m_{1}\right)$ join the GRS in period $t=1$ and $m_{2} \leq m_{1}$ countries $\left(i=1, \ldots, m_{2}\right)$ stay in the GRS in period $t=2$. Then, given emission taxes imposed by the non-participating countries $\tau_{t}^{j}\left(j=m_{t}+1, \ldots, n\right)$, the CA seeks to implement the solution of the optimization problem (19) subject to equations (3), (1), and $\tau_{t}^{i} \geq 0(i \in G R S, t=1,2)$. Thus the CA's tax goal $\tau_{1}^{T G}, \tau_{2}^{T G}$ is given by

$$
\begin{aligned}
\tau_{1}^{T G}= & \eta \beta\left[\frac{n \bar{e}\left\{\phi\left[m_{1}+m_{2} \delta(1-\gamma)(2-\gamma)\right]+m_{1} m_{2}^{2} \eta^{2} \beta\right\}}{\phi^{2}+\phi \eta^{2} \beta\left[m_{1}^{2}+m_{2}^{2}+m_{1} m_{2} \delta(1-\gamma)^{2}\right]+m_{1}^{2} m_{2}^{2} \eta^{4} \beta^{2}}\right. \\
& \left.-\frac{\eta \mathcal{T}_{1}\left\{\phi\left[m_{1}+m_{2} \delta(1-\gamma)^{2}\right]+m_{1} m_{2}^{2} \eta^{2} \beta\right\}+\eta \mathcal{T}_{2} \phi m_{2} \delta(1-\gamma)}{\phi^{2}+\phi \eta^{2} \beta\left[m_{1}^{2}+m_{2}^{2}+m_{1} m_{2} \delta(1-\gamma)^{2}\right]+m_{1}^{2} m_{2}^{2} \eta^{4} \beta^{2}}\right], \\
\tau_{2}^{T G}= & m_{2} \beta \eta \frac{(1-\gamma) s_{1}+n \bar{e}-\eta \mathcal{T}_{2}}{\phi+m_{2}^{2} \eta^{2} \beta} \\
= & m_{2} \eta \beta \frac{n \bar{e}\left[\phi(2-\gamma)+m_{1}^{2} \eta^{2} \beta\right]-\eta \mathcal{T}_{1} \phi(1-\gamma)-\eta \mathcal{T}_{2}\left(\phi+m_{1}^{2} \eta^{2} \beta\right)}{\phi^{2}+\phi \eta^{2} \beta\left[m_{1}^{2}+m_{2}^{2}+m_{1} m_{2} \delta(1-\gamma)^{2}\right]+m_{1}^{2} m_{2}^{2} \eta^{4} \beta^{2}}
\end{aligned}
$$

where $\mathcal{T}_{t}$ denotes the sum of the taxes imposed by all non-participating countries in

\footnotetext{
${ }^{4}$ We neglect the agency problems that might arise when member countries delegate the power to set the parameters of the GRS to the CA. We discuss alternative mechanisms to a central agency in Section 5 .
} 
period t, i.e.,

$$
\mathcal{T}_{t}=\sum_{j=m_{t}+1}^{n} \tau_{t}^{j} .
$$

This yields the following stocks $s_{1}^{T G}$ and $s_{2}^{T G}$ :

$$
\begin{aligned}
& s_{1}^{T G}=\phi\left[\frac{n \bar{e}\left\{\phi+m_{2} \eta^{2} \beta\left[m_{2}-m_{1} \delta(1-\gamma)\right]\right\}-\eta \mathcal{T}_{1}\left(\phi+m_{2}^{2} \eta^{2} \beta\right)}{\phi^{2}+\phi \eta^{2} \beta\left[m_{1}^{2}+m_{2}^{2}+m_{1} m_{2} \delta(1-\gamma)^{2}\right]+m_{1}^{2} m_{2}^{2} \eta^{4} \beta^{2}}\right. \mathcal{T}_{2} m_{1} m_{2} \eta^{3} \beta \delta(1-\gamma) \\
&\left.+\frac{(1-\gamma) s_{1}+n \bar{e}-\eta \mathcal{T}_{2}}{\phi^{2}+\phi \eta^{2} \beta\left[m_{1}^{2}+m_{2}^{2}+m_{1} m_{2} \delta(1-\gamma)^{2}\right]+m_{1}^{2} m_{2}^{2} \eta^{4} \beta^{2}}\right], \\
& s_{2}^{T G}= \frac{\left(1+m_{2}^{2} \eta^{2} \beta\right.}{\phi^{2}} \\
&=\phi \frac{n \bar{e}\left[\phi(2-\gamma)+m_{1}^{2} \eta^{2} \beta\right]-\eta \mathcal{T}_{1} \phi(1-\gamma)-\eta \mathcal{T}_{2}\left(\phi+m_{1}^{2} \eta^{2} \beta\right)}{\phi^{2}+\phi \eta^{2} \beta\left[m_{1}^{2}+m_{2}^{2}+m_{1} m_{2} \delta(1-\gamma)^{2}\right]+m_{1}^{2} m_{2}^{2} \eta^{4} \beta^{2}} .
\end{aligned}
$$

The proof of Proposition 3 is given in the appendix.

\section{Corollary 1}

If all $n$ countries join the GRS in period $t=1$ and remain in the GRS in period $t=2$ (i.e., $m_{1}=m_{2}=n$ in Proposition 3), $\mathcal{T}_{t}=0$ and the $C A$ 's taxgoal $\tau_{t}^{T G}$ and the corresponding stocks $s_{t}^{T G}$ equal the taxes $\tau_{t}^{\star}$ and stocks $s_{t}^{\star}$ of the global social optimum as defined in equations (10) and (11).

Corollary 1 follows from Proposition 3 by calculating $\tau_{t}^{T G}$ and $s_{t}^{T G}$ for $m_{1}=m_{2}=n$.

Given the parameter settings by the CA, countries choose national emission taxes, and participating countries transfer national emission tax revenues to the global fund $f_{1}$. At the end of period $t=1$, the CA reimburses fraction $\alpha_{1}$ of the fund $f_{1}$ to member countries. Each member country receives a share in proportion to the relative greenhouse gas reductions compared to the baseline emissions $\Theta_{1}$. The remaining fund earns interest $\rho$ and is transferred to the next period's fund $f_{2}$.

At the beginning of period $t=2$, member countries decide whether to leave the GRS. If they do, they lose all claims on payments from the global fund. The CA announces refunding share $\alpha_{2}$ and baseline emission $\Theta_{2}$. In general, these settings depend on the number of countries still in the GRS. Again, all countries set national emission tax levels, and member countries transfer emission tax revenues to the global fund. At the end of period $t=2$, the CA refunds share $\alpha_{2}$ to the member countries according to the refunding rule. If $\alpha_{2}<1$, the remaining fund $\left(1-\alpha_{2}\right) f_{2}$ is distributed equally among the member countries by lump-sum transfer. 
For the refund $r_{t}^{i}$ that a member country $i$ receives in period $t$, we assume the following refunding rule:

$$
r_{t}^{i}=\max \left[\alpha_{t} f_{t} \frac{\Theta_{t}-\bar{e}+\eta \tau_{t}^{i}}{\sum_{j \in G R S}^{n}\left(\Theta_{t}-\bar{e}+\eta \tau_{t}^{j}\right)}, 0\right], \quad t=1,2 .
$$

The refunding formula captures the basic idea of a GRS: the refund a country $i$ receives is proportional to the relative emission reductions it achieves. The assets of the fund $f_{t}$ at the end of period $t$ before repayments are made is given by

$$
\begin{aligned}
& f_{1}=\sum_{i \in G R S}\left[f_{0}^{i}+\tau_{1}^{i}\left(\bar{e}-\eta \tau_{1}^{i}\right)\right] \\
& f_{2}=(1+\rho)\left(1-\alpha_{1}\right) f_{1}+\sum_{i \in G R S} \tau_{2}^{i}\left(\bar{e}-\eta \tau_{2}^{i}\right) .
\end{aligned}
$$

For convenience, we assume that interest rate $\rho$ corresponds to discount factor $\delta$, i.e.:

$$
\rho=\frac{1}{\delta}-1
$$

In the following, we investigate the incentives for reducing greenhouse gas emissions created by the GRS in two steps. First we assume that $m_{1}$ countries join the GRS in period $t=1$ and all $m_{1}$ countries decide to stay in the GRS in period $t=2$. We show that under these assumptions the GRS can always implement the favored tax goal as described by Proposition 3. Second, we investigate the conditions under which the GRS is self-enforcing, i.e., provided that $m_{1}$ countries joined the GRS in period $t=1$, no country has an incentive to leave the GRS in period $t=2$. Again, we show that the CA can set the GRS parameters in such a way that no country will leave the GRS in period $t=2$.

\subsection{Full Participation Outcome}

We assume in this section that $m_{1}$ countries join the GRS in period $t=1$ and all $m_{1}$ countries decide to stay in the GRS in period $t=2$ (i.e., $m_{2}=m_{1}$ ). We will call this the full participation assumption. Given this assumption, we derive the necessary and sufficient conditions for all participating countries to choose the emission taxes $\tau_{1}^{T G}$, $\tau_{2}^{T G}$ as defined in Proposition 3. In addition, we show that there are initial payments $f_{0}^{i}$, refunding shares $\alpha_{1}$ and $\alpha_{2}$, and baseline emissions $\Theta_{1}$ and $\Theta_{2}$ ensuring that the tax goal is achieved. For more convenient presentation, we first assume that the refunding 
share $r_{t}^{i}>0$ for all countries $i$ participating in the GRS. We will see ex post that this assumption is verified in the unique subgame perfect equilibrium. Thus, assuming that $m_{1}$ countries $i$ participate in the global refunding system, each country $i$ solves the following optimization problem, given the choices of the CA and all other countries:

$$
\begin{aligned}
\min _{\tau_{1}^{i}, \tau_{2}^{i}} & \left\{\sum_{t=1}^{2} \delta^{t-1}\left[\frac{\phi}{2}\left(\tau_{t}^{i}\right)^{2}+\frac{\beta}{2} s_{t}^{2}+\tau_{t}^{i}\left(\bar{e}-\eta \tau_{t}^{i}\right)-\alpha_{t} f_{t} \frac{\Theta_{t}-\bar{e}+\eta \tau_{t}^{i}}{\sum_{j=1}^{m_{1}}\left(\Theta_{t}-\bar{e}+\eta \tau_{t}^{j}\right)}\right]\right. \\
+ & \left.f_{0}^{i}-\delta\left(1-\alpha_{2}\right) \frac{f_{2}}{m_{1}}\right\},
\end{aligned}
$$

subject to equations (3), (1), (24), and $\tau_{t}^{i} \geq 0, \quad t=1,2$.

This implies the following Lagrangian:

$$
\begin{aligned}
\mathcal{L}= & \sum_{t=1}^{2}\left\{\delta^{t-1}\left[\frac{\phi}{2}\left(\tau_{t}^{i}\right)^{2}+\frac{\beta}{2} s_{t}^{2}+\tau_{t}^{i}\left(\bar{e}-\eta \tau_{t}^{i}\right)-\alpha_{t} f_{t} \frac{\Theta_{t}-\bar{e}+\eta \tau_{t}^{i}}{\sum_{j=1}^{m_{1}}\left(\Theta_{t}-\bar{e}+\eta \tau_{t}^{j}\right)}\right]\right. \\
& \left.+\lambda_{t}^{G R S}\left[(1-\gamma) s_{t-1}+\sum_{j=1}^{n}\left(\bar{e}-\eta \tau_{t}^{j}\right)-s_{t}\right]\right\}+f_{0}^{i}-\delta\left(1-\alpha_{2}\right) \frac{f_{2}}{m_{1}}
\end{aligned}
$$

where $\lambda_{t}^{G R S}$ denote the Lagrange multipliers or shadow prices of the stock of greenhouse gases $s_{t}$, and the fund $f_{t}$ is given by equations $(24)$.

The necessary conditions for an optimal solution are

$$
\begin{aligned}
\frac{\partial \mathcal{L}}{\partial \tau_{1}^{i}}= & \phi \tau_{1}^{i}-\eta \lambda_{1}^{G R S}+\left(\bar{e}-2 \eta \tau_{1}^{i}\right)\left\{1-\frac{\left(1-\alpha_{1}\right)\left(1-\alpha_{2}\right)}{m_{1}}-\frac{\left(1-\alpha_{1}\right) \alpha_{2}\left(\Theta_{2}-\bar{e}+\eta \tau_{2}^{i}\right)}{\sum_{j=1}^{m_{1}}\left(\Theta_{2}-\bar{e}+\eta \tau_{2}^{j}\right)}\right. \\
& \left.-\frac{\alpha_{1}\left(\Theta_{1}-\bar{e}+\eta \tau_{1}^{i}\right)}{\sum_{j=1}^{m_{1}}\left(\Theta_{1}-\bar{e}+\eta \tau_{1}^{j}\right)}\right\}-\eta \alpha_{1} f_{1} \frac{\sum_{j \neq i, j \in G R S}\left(\Theta_{1}-\bar{e}+\eta \tau_{1}^{j}\right)}{\left[\sum_{j=1}^{m_{1}}\left(\Theta_{1}-\bar{e}+\eta \tau_{1}^{j}\right)\right]^{2}}=0, \quad \text { (28a) } \\
\frac{\partial \mathcal{L}}{\partial \tau_{2}^{i}}= & \delta \phi \tau_{2}^{i}-\eta \lambda_{2}^{G R S}+\delta\left(\bar{e}-2 \eta \tau_{2}^{i}\right)\left\{1-\frac{1-\alpha_{2}}{m_{1}}-\frac{\alpha_{2}\left(\Theta_{2}-\bar{e}+\eta \tau_{2}^{i}\right)}{\sum_{j=1}^{m_{1}}\left(\Theta_{2}-\bar{e}+\eta \tau_{2}^{j}\right)}\right\} \\
& -\delta \eta \alpha_{2} f_{2} \frac{\sum_{j \neq i, j \in G R S}\left(\Theta_{2}-\bar{e}+\eta \tau_{2}^{j}\right)}{\left[\sum_{j=1}^{m_{1}}\left(\Theta_{2}-\bar{e}+\eta \tau_{2}^{j}\right)\right]^{2}}=0, \quad \text { (28c) } \\
\frac{\partial \mathcal{L}}{\partial s_{1}}= & \beta s_{1}+(1-\gamma) \lambda_{2}^{G R S}-\lambda_{1}^{G R S}=0, \\
\frac{\partial \mathcal{L}}{\partial s_{2}}= & \delta \beta s_{2}-\lambda_{2}^{G R S}=0 .
\end{aligned}
$$

If the Lagrangian is strictly convex (at least along the optimal path), these necessary conditions, together with the conditions $\tau_{t}^{i} \geq 0(t=1,2)$, are also sufficient for a unique 
solution. However, strict convexity of the Lagrangian (27) is not generally guaranteed and may hinge upon the CA's choice of GRS parameters $f_{0}^{i}, \alpha_{t}$, and $\Theta_{t}$. The following proposition establishes a sufficient condition enabling the CA to ensure the strict convexity of the Lagrangian.

\section{Proposition 4 (Sufficient condition for strict convexity)}

Given the maximization problem (26) subject to equations (3), (1), (24), and $\tau_{t}^{i} \geq 0$ $(t=1,2)$, the $C A$ can always set $f_{0}^{i}$ such that the resulting Lagrangian (27) is strictly convex, if the following condition holds:

$$
\phi \geq 2 \eta
$$

The proof of Proposition 4 is given in the appendix.

For the remainder of the paper, we assume that condition (29) holds.

We next calculate the equilibrium tax rates. From the necessary conditions (28c) and (28d) we obtain for the shadow prices $\lambda_{t}^{G R S}$

$$
\lambda_{1}^{G R S}=\beta\left[s_{1}+\delta(1-\gamma) s_{2}\right], \quad \lambda_{2}^{G R S}=\delta \beta s_{2} .
$$

As all $m_{1}$ countries are identical, we focus on symmetric Nash equilibria. Thus, all countries $i \in G R S$ set the same emission taxes, i.e., $\tau_{t}^{i}=\tau_{t} \forall i \in G R S$. Then inserting equations (30) into conditions (28a) and (28b) yields the following two necessary conditions for country $i$ :

$$
\begin{aligned}
\phi \tau_{1} & =\eta \beta\left[s_{1}+\delta(1-\gamma) s_{2}\right]+\frac{\left(m_{1}-1\right) \eta \alpha_{1} f_{1}}{m_{1}^{2}\left(\Theta_{1}-\bar{e}+\eta \tau_{1}\right)}-\left(\bar{e}-2 \eta \tau_{1}\right) \frac{m_{1}-1}{m_{1}}, \\
\phi \tau_{2} & =\eta \beta s_{2}+\frac{\left(m_{1}-1\right) \eta \alpha_{2} f_{2}}{m_{1}^{2}\left(\Theta_{2}-\bar{e}+\eta \tau_{2}\right)}-\left(\bar{e}-2 \eta \tau_{2}\right) \frac{m_{1}-1}{m_{1}} .
\end{aligned}
$$

By inserting $s_{t}$ and $f_{t}$ from equations (3) and (24), we derive a system of two quadratic equations in $\tau_{1}$ and $\tau_{2}$, which yields up to four real solutions for the vector $\left(\tau_{1}, \tau_{2}\right)$. If, however, condition (29) holds and $f_{0}^{i}$ is sufficiently high for the Lagrangian to be strictly convex, then the solution is unique (i.e., there is only one real solution with $\tau_{t} \geq 0$, $t=1,2)$. Hence, given the GRS parameters $f_{0}^{i}, \alpha_{t}$, and $\Theta_{t}$ announced by the CA, there exists a unique subgame perfect equilibrium where all countries choose emission taxes $\tau_{1}$ and $\tau_{2}$ determined by the non-negative solutions of the system of equations (31).

We now turn to the question of how the CA must set the GRS parameters $f_{0}^{i}, \alpha_{t}$, and $\Theta_{t}$ in order to achieve the tax goal derived in Proposition 3. For any tax goal $\tau_{1}$ and 
$\tau_{2}$ the CA seeks to implement, the CA has to set the GRS parameters $f_{0}^{i}, \alpha_{t}, \Theta_{t}$ such that equations (31) hold. Obviously, (31) is an overdetermined system of equations, as we have only two equations for the five unknown GRS paremeters $f_{i}^{0}, \alpha_{t}$, and $\Theta_{t}$. This implies that the CA has some degree of freedom about how to implement the tax goal. This degree of freedom is important in two ways. First, it guarantees that the CA can set the policy parameters so that the individual country's optimization problem is strictly convex (see Proposition 4). Second, in the next subsection we consider the conditions under which no country has an incentive to leave the agreement at the beginning of period $t=2$. We will see that this implies further restrictions on the GRS parameters. ${ }^{5}$ In the following proposition we show that, for any given $f_{0}^{i}$, the CA can choose $\Theta_{t}$ and $\alpha_{t}$ such that the tax goal is a symmetric subgame perfect equilibrium in the dynamic game in which all countries minimize their own costs and damages, given that $m_{1}$ countries participate in the GRS in both periods and given the choices of the $\mathrm{CA}$ and all other countries.

\section{Proposition 5 (Feasibility of the tax goal under full participation)}

Suppose that $m_{1}$ countries participate in the GRS in both periods and that condition (29) holds. Then, for any given values of $f_{0}^{i}$, the CA can find feasible parameter values for $\alpha_{t}$ and $\Theta_{t}(t=1,2)$ such that the tax goal as given by equations (20) and (22) is supported as a subgame perfect equilibrium.

The proof of Proposition 5 is given in the appendix.

The following corollary derives directly from combining the results of Propositions 4 and 5 .

\section{Corollary 2}

Given the assumptions of Proposition 5, the CA can find parameter values $f_{0}^{i}, \alpha_{t}$ and $\Theta_{t}$ such that the tax goal as given by equations (20) and (22) is the unique subgame perfect equilibrium.

The proof of Corollary 2 is given in the appendix.

Thus, under the assumption that $m_{1}$ countries participate in the GRS in both periods, the CA can set the GRS parameters $f_{0}^{i}, \alpha_{t}$, and $\Theta_{t}$ such that all countries choose emission taxes equivalent to the tax goal of the CA. In the next subsection we relax the assumption that all countries will stay in the GRS in the second period per definitionem

\footnotetext{
${ }^{5}$ In fact, both convexity and self-enforcement imply minimum levels of the initial fee $f_{0}^{i}$.
} 
and investigate the conditions under which countries voluntarily choose to remain in the GRS.

\subsection{Self-enforcement of the GRS}

Now we turn to the conditions under which the GRS is self-enforcing, i.e., given that $m_{1}$ countries joined the GRS in period $t=1$, no country has an incentive to leave the GRS at the beginning of period $t=2$.

To discuss this participation constraint at the beginning of period 2, we examine the consequence of $n-m_{2}$ countries $i=m_{2}+1, \ldots, n$ not taking part in the GRS in period $t=2$, where $m_{2} \leq m_{1}$ and $m_{1}-m_{2}$ is the number of countries leaving the GRS at the beginning of period $t=2$. Suppose that each country $i=m_{2}+1, \ldots, n$ that does not participate in the GRS in period $t=2$ only minimizes their own costs and damages. ${ }^{6}$ In other words, they solve the following optimization problem :

$$
\min _{\tau_{2}^{i}}\left\{\frac{\phi}{2}\left(\tau_{2}^{i}\right)^{2}+\frac{\beta}{2} s_{2}^{2}\right\}
$$

subject to equations (3), (1), and $\tau_{2}^{i} \geq 0, i \notin G R S$.

According to equation (3) the stock $s_{2}$ of greenhouse gases depends on the stock $s_{1}$ of the former period, the emissions of countries $i=m_{2}+1, \ldots, n$, and the emissions of all other countries $j \neq i$. The countries $j=1, \ldots, m_{2}$ are assumed to remain in the GRS, and the CA will set $\alpha_{2}$ and $\Theta_{2}$ in their interests. That is, the CA's tax goal is the tax $\tau_{2}^{T G}$ that minimizes the costs and damages of all member countries of the GRS, given the emission taxes of all non-participating countries. Suppose that $m_{1}$ countries joined the GRS in period $t=1$ and the implemented tax goal in the first period equaled tax $\tau_{1}^{T G}$ as given by equation (20a). Then the CA's tax goal in period $t=2$, according to Proposition 3, is given by

$$
\begin{aligned}
\tau_{2}^{T G} & =m_{2} \eta \beta \frac{\left[(1-\gamma) s_{1}^{T G}+n \bar{e}-\eta \mathcal{T}_{2}\right]}{\phi+m_{2}^{2} \eta^{2} \beta} \\
s_{2}^{T G} & =\phi \frac{(1-\gamma) s_{1}^{T G}+n \bar{e}-\eta \mathcal{T}_{2}}{\phi+m_{2}^{2} \eta^{2} \beta}
\end{aligned}
$$

where $\mathcal{T}_{2}=\sum_{i=m_{2}+1}^{n} \tau_{2}^{j}$ is the sum of the emission taxes of the countries not participating in the GRS in period $t=2$.

\footnotetext{
${ }^{6}$ We neglect the eventuality of $m_{1}-m_{2}$ countries forming a separate GRS for the last period.
} 
Analogously to the previous subsection, the following proposition establishes that the CA can implement the taxgoal as defined in equations (33) by the appropriate choice of GRS parameters $\Theta_{2}$ and $\alpha_{2}$ as the unique Nash equilibrium of the game in period $t=2$, in which all countries $i\left(i=1, \ldots, m_{2}\right)$, given $\tau_{2}^{j}\left(j=m_{2}+1, \ldots, n\right), \alpha_{2}$, and $\Theta_{2}$, solve the optimization problem

$$
\begin{aligned}
\min _{\tau_{2}^{i}} & \left\{\frac{\phi}{2}\left(\tau_{2}^{i}\right)^{2}+\frac{\beta}{2} s_{2}^{2}+\tau_{2}^{i}\left(\bar{e}-\eta \tau_{2}^{i}\right)-\alpha_{2} f_{2} \frac{\Theta_{2}-\bar{e}+\eta \tau_{2}^{i}}{\sum_{j=1}^{m_{2}}\left(\Theta_{2}-\bar{e}+\eta \tau_{2}^{j}\right)}\right. \\
& \left.-\left(1-\alpha_{2}\right) \frac{f_{2}}{m_{2}}\right\},
\end{aligned}
$$

subject to equations (3), (1), (24), and $\tau_{2}^{i} \geq 0, i \in G R S$.

\section{Proposition 6 (Feasibility of the tax goal in period $t=2$ )}

Suppose that $m_{2}$ countries participate in the GRS in period $t=2$ and that condition (29) holds. Then the CA can find parameter values for $\alpha_{2}$ and $\Theta_{2}$ for any given values of $f_{0}^{i}$ such that the tax goal as given by equations (33a) and (33b) is supported as a Nash equilibrium. If, in addition, the minimization problems of all countries $i$ are convex, the tax goal is the unique Nash equilibrium.

The proof of Proposition 6 is given in the appendix.

Given that the CA implements the optimal tax goal $\tau_{2}^{T G}$ for member countries of the GRS, the emission taxes for the member countries and the emission taxes for the countries $j=m_{2}+1, \ldots, n$ not participating in the GRS in period $t=2$ is given by the following proposition:

\section{Proposition 7 (Nash equilibrium in period $t=2$ )}

Suppose that $m_{1}$ countries join the GRS in period $t=1, m_{2}$ countries stay in the GRS in period $t=2$, and the CA successfully implements the optimal tax goal for member countries of the GRS in both periods. Then the emission taxes $\tau_{2}^{G R S}$ of the countries not participating in the GRS and the emission taxes $\tau_{2}^{G R S}$ of the countries staying in the GRS are given by

$$
\begin{aligned}
\tau_{2}^{G R S}\left(m_{2}\right) & =\eta \beta \frac{(1-\gamma) s_{1}^{T G}+n \bar{e}}{\phi+\eta^{2} \beta\left[\left(m_{1}-m_{2}\right)+m_{2}^{2}\right]}, \\
\tau_{2}^{G R S}\left(m_{2}\right) & =m_{2} \eta \beta \frac{(1-\gamma) s_{1}^{T G}+n \bar{e}}{\phi+\eta^{2} \beta\left[\left(m_{1}-m_{2}\right)+m_{2}^{2}\right]} .
\end{aligned}
$$


For the stock $s_{2}\left(m_{2}\right)$ of greenhouse gases this implies

$$
s_{2}\left(m_{2}\right)=\phi \frac{(1-\gamma) s_{1}^{T G}+n \bar{e}}{\phi+\eta^{2} \beta\left[\left(m_{1}-m_{2}\right)+m_{2}^{2}\right]} .
$$

The proof of Proposition 7 is given in the appendix.

Having established the outcome in period $t=2$ if $m_{1}-m_{2}$ countries leave the GRS in period $t=2$, we can now turn to the question of what condition makes it beneficial for a country $i$ to leave the GRS. Assuming that all countries act in their own interests, a country $i$ will leaves the GRS in period $t=2$ if the costs $C^{G R S}\left(m_{2}-1\right)$ of leaving the GRS, given by

$$
C^{\text {GRS }}\left(m_{2}-1\right)=\frac{\phi}{2}\left(\tau_{2}^{\text {GRS }}\left(m_{2}-1\right)\right)^{2}+\frac{\beta}{2}\left(s_{2}\left(m_{2}-1\right)\right)^{2},
$$

are smaller than the costs of staying in the GRS, $C^{G R S}\left(m_{2}\right)$ :

$$
C^{G R S}\left(m_{2}\right)=\frac{\phi}{2}\left(\tau_{2}^{G R S}\left(m_{2}\right)\right)^{2}+\frac{\beta}{2}\left(s_{2}\left(m_{2}\right)\right)^{2}-\frac{m_{1}\left(1-\alpha_{1}\right)}{m_{2} \delta}\left[f_{0}^{i}+\tau_{1}^{\star}\left(\bar{e}-\eta \tau_{1}^{\star}\right)\right] .
$$

Denoting the cost difference between staying in the GRS and leaving the GRS, given that $m_{2}$ countries stay in the GRS, by $\Delta C\left(m_{2}\right)$

$$
\Delta C\left(m_{2}\right)=C^{G R S}\left(m_{2}\right)-C^{G R S}\left(m_{2}-1\right),
$$

country $i$ will leave the GRS if $\Delta C\left(m_{2}\right) \geq 0$.

In the following proposition we show that the GRS is self-enforcing in the sense that for all $m_{2}=1, \ldots, n$ the CA can set $f_{0}^{i}$ such that $\Delta C\left(m_{2}\right)<0$ and so no country has an incentive to leave the GRS in period $t=2$.

\section{Proposition 8 (Self-enforcement of the GRS)}

Suppose that $m_{2}$ countries are members of the GRS at the beginning of period $t=2$, a member country $i$ will leave the GRS in period $t=2$ if $\Delta C\left(m_{2}\right) \geq 0$, and countries leaving the GRS minimize (32) subject to equations (3), (1), (33), $\tau_{2}^{j} \geq 0$ ( $\left.j \notin G R S\right)$. Then the CA can set the initial fee $f_{0}^{i}$ such that no country will leave the GRS in period $t=2$.

The proof of Proposition 8 is given in the appendix.

Proposition 8 says that the CA can always set $f_{0}^{i}$ so that there is no incentive for any country to leave the GRS, which implies that all countries will remain in the GRS. Accordingly, the GRS is self-enforcing. 
In summary, we have shown that for any number of countries $m_{1}$ joining the GRS in period $t=1$ a self-enforcing GRS can be designed such that the tax goal as given by Proposition 3 is achieved for both periods. If all countries join the GRS in period $t=1$ (i.e., $m_{1}=n$ ), then the GRS achieves the global social optimum.

\section{Discussion}

We have designed a global refunding scheme inducing countries to follow a socially optimal path of abatement. Within the formal representation of our model we have shown that, once all countries have joined, the GRS can achieve the global social optimum. Moreover, it is self-enforcing in the sense that no country has an incentive to leave the GRS. However, our formal results rest on a number of strong assumptions, some of which we will discuss in the following. We also indicate some important avenues for further research.

First we discuss particular institutional details of the global refunding system proposed in this paper. We have assumed that the GRS is operated by a central agency acting in the interests of member countries. An equivalent institution would be a body governing the GRS in which each member country has one delegate with one vote and decisions are taken by simple majority rule. As member countries are homogeneous and their interests are thus aligned, majority decisions would yield the same outcomes as delegation to a central authority.

Next, the system relies on the determination of the path of baseline emissions $\Theta_{1}$ and $\Theta_{2}$ by the central authority. Alternative refunding formulas are conceivable that do not rely on additional information beyond the emission reductions actually realized. For instance, a country's refund might depend solely on the proportion of emission reductions it achieves within a given period compared to previous periods. In principle, such a scheme can generate similarly powerful abatement incentives and also yields a self-enforcing property for the GRS. However, the analytical complexity increases substantially as a further intertemporal incentive effect occurs because strong abatement in a particular period increases refund costs in subsequent periods.

Second, participation in the GRS in period $t=1$ is a delicate issue as the scheme requires initial monetary commitment by all countries. As in the literature on public goods, this can be justified by cancelling the initial agreement if one country does not 
sign the commitment. That is, the GRS will not be established unless all countries participate. ${ }^{7}$ A next step would be to examine sequential procedures for inducing countries to participate. ${ }^{8}$ The crucial issue is whether the strong incentives to abate generated by the system developed in this paper can be built up over time.

Third, in our model we assume completely symmetric countries. In fact, countries differ both in the costs of emission abatement and in the expected damages from climate change. Most studies indicate that the economic and social impacts of climate change would be distributed very unevenly across the globe. In particular, there is a prospect of large damages to developing countries in the tropics (see, e.g., Tol 2006). Such countries will not only have higher marginal damages, they also may lack the funds to participate in the GRS. Whether it is possible to design an efficient GRS where all countries participate but only a subset of countries (i.e. "rich" countries) pay an initial fee and are eligible to receive non-refunded funds at the end of the life-time, is an important avenue for further research on narrowing the gap between the theoretical concept and its practical applications.

\section{Conclusion}

In this paper we have introduced an alternative international climate change mitigation agreement, the global refunding scheme (GRS), which is a potential candidate for replacing or succeeding existing agreements such as the Kyoto protocol. The basic idea of the GRS is that each country is free to set its carbon emission tax but all tax revenues of member countries are collected in a global fund and partly reimbursed to member countries in proportion to the relative emission reductions they have achieved within a given period and compared to some given baseline emission levels.

Within a simple model framework we have shown that the GRS can completely overcome the the free-riding problem involved in the provision of the global public good "mitigation of climate change" and thus implement globally social optimal levels of emission abatement. Moreover, the GRS is self-enforcing in the sense that compliance with the agreement is in the interests of all member countries and therefore does not rely on a supranational body with the power to prosecute infringement of the agree-

\footnotetext{
${ }^{7}$ It can easily be seen from Propositions 1 and 2 that joining the GRS is more profitable for an individual country than the fully decentralized solution.

${ }^{8}$ Such procedures have been proposed and examined in the literature on the private supply of public goods (Andreoni 1998, Varian 1994, Lange 2006).
} 
ment.

However, participation by all countries in the GRS requires initial monetary payments into the fund and the threat that the GRS will only materialize if all countries participate. Sequential procedures might be able to overcome this problem. This issue and accounting for heterogeneous countries are promising avenues for further research. 


\section{Appendix}

\section{Proof of Proposition 1}

Inserting equation (3) into equation (9) yields the following system of 2 linear and independent equations for the optimal emission taxes $\tau_{1}^{\star}$ and $\tau_{2}^{\star}$ :

$$
\begin{aligned}
\phi \tau_{1}= & n^{2} \eta \beta \bar{e}[1+\delta(1-\gamma)(2-\gamma)]-n^{2} \eta^{2} \beta\left\{\tau_{1}\left[1+\delta(1-\gamma)^{2}\right]\right. \\
& \left.+\tau_{2} \delta(1-\gamma)\right\} \\
\phi \tau_{2}= & n^{2} \eta \beta \bar{e}(2-\gamma)-n^{2} \eta^{2} \beta\left[\tau_{1}(1-\gamma)+\tau_{2}\right]
\end{aligned}
$$

the unique solution of which is given by equations (10).

Inserting $\tau_{1}^{\star}$ and $\tau_{2}^{\star}$ into the equation of motion for the greenhouse gas stock (3), we derive equations (11) for the optimal stocks $s_{1}^{\star}$ and $s_{2}^{\star}$.

\section{Proof of Proposition 2}

The set of subgame perfect equilibria is determined by the solution of the set of necessary and sufficient linear conditions (16). In the subgame perfect equilibrium, all countries $i$ set the same emission taxes, as the right hand side of condition (16) is identical across countries. Thus we can reduce (16) to a set of 2 linear equations for the two unknowns $\hat{\tau}_{1}$ and $\hat{\tau}_{2}$ if we also insert the equation of motion (3) for the stocks of greenhouse gases $s_{t}$ and substitute emissions via equation (1):

$$
\begin{aligned}
& \phi \tau_{1}=n \eta \beta \bar{e}[1+\delta(1-\gamma)(2-\gamma)]-n^{2} \eta^{2} \beta\left\{\tau_{1}\left[1+\delta(1-\gamma)^{2}\right]+\tau_{2} \delta(1-\gamma)\right\} \\
& \phi \tau_{2}=n \eta \beta \bar{e}(2-\gamma)-n \eta^{2} \beta\left[\tau_{1}(1-\gamma)+\tau_{2}\right] .
\end{aligned}
$$

As these two equations are linear and independent, there exists a unique solution given by equations (17).

We derive equations (18) for the stocks of greenhouse gases by inserting equations (17) into the equation of motion (3).

\section{Proof of Proposition 3}

Let countries $i=1, \ldots, m_{1}$ join the GRS in period $t=1$, and let countries $i=$ 
$1, \ldots, m_{2} \leq m_{1}$ stay in the GRS in period $t=2$. Denote the sum of the emission taxes imposed by non-participating countries in period $t$ by $\mathcal{T}_{t}$. Then the Lagrangian of the optimization problem (19) subject to equations (3), (1), and $\tau_{t}^{i} \geq 0, i \in G R S, t=1,2$, is given by

$$
\begin{aligned}
\mathcal{L}= & \sum_{t=1}^{2}\left\{\delta^{t-1}\left[\sum_{j=1}^{m_{t}} \frac{\phi}{2}\left(\tau_{t}^{j}\right)^{2}+m_{t} \frac{\beta}{2} s_{t}^{2}\right]\right. \\
& \left.+\lambda_{t}^{T G}\left[(1-\gamma) s_{t-1}+n \bar{e}-\eta\left(\sum_{j=1}^{m_{t}} \tau_{t}^{j}+\mathcal{T}_{t}\right)-s_{t}\right]\right\},
\end{aligned}
$$

where $\lambda_{t}^{T G}$ denotes the Langrange multiplier or shadow price for the global stock of greenhouse gases in period $t$. The first-order conditions for an optimal solution are

$$
\begin{aligned}
& \frac{\partial \mathcal{L}}{\partial \tau_{t}^{i}}=\phi \tau_{t}^{i} \delta^{t-1}-\eta \lambda_{t}^{T G}=0, \quad i=1, \ldots, m_{t}, t=1,2, \\
& \frac{\partial \mathcal{L}}{\partial s_{t}}=m_{t} \beta s_{t} \delta^{t-1}+(1-\gamma) \lambda_{t+1}^{T G}-\lambda_{t}^{T G}=0, \quad t=1,2,
\end{aligned}
$$

where $\lambda_{3}^{T G}=0$. Due to the strict convexity of the Lagrangian these necessary conditions are also sufficient for a unique solution. Equation (A.3b) can be solved by backward induction to yield

$$
\lambda_{t}^{T G}=\beta \sum_{k=t}^{2} m_{k} \delta^{k-1}(1-\gamma)^{k-t} s_{k}, \quad t=1,2 .
$$

Inserting equations (A.4) and (3) into equation (A.3a) yields the $m_{1}+m_{2}$ necessary and sufficient conditions for the $m_{1}+m_{2}$ emission taxes $\tau_{t}^{i}$. As all countries are symmetric, all countries will exhibit the same optimal taxes $\tau_{t}$, and the $m_{1}+m_{2}$ necessary and sufficient condition reduce to the following two linear and independent equations:

$$
\begin{aligned}
\phi \tau_{1}= & \eta \beta\left\{n \bar{e}\left[m_{1}+m_{2} \delta(1-\gamma)(2-\gamma)\right]-\eta \mathcal{T}_{1}\left[m_{1}+m_{2} \delta(1-\gamma)^{2}\right]\right. \\
& \left.-m_{2} \eta \mathcal{T}_{2} \delta(1-\gamma)-m_{1} \eta \tau_{1}\left[m_{1}+m_{2} \delta(1-\gamma)^{2}\right]-m_{2}^{2} \eta \tau_{2} \delta(1-\gamma)\right\} \\
\phi \tau_{2}= & m_{2} \eta \beta\left[n \bar{e}(2-\gamma)-\eta \mathcal{T}_{1}(1-\gamma)-\eta \mathcal{T}_{2}-m_{1} \eta \tau_{1}(1-\gamma)-m_{2} \eta \tau_{2}\right] .
\end{aligned}
$$

The unique solution is given by equations (20).

We derive equations (22) for the stocks of greenhouse gases by inserting equations (20) into the equation of motion (3). 


\section{Proof of Proposition 4}

The Lagrangian (27) is strictly convex if its Hessian is positive definite. A matrix is positive definite if the determinants of all principal minors are strictly positive. Differentiating the necessary conditions (28) with respect to $\tau_{1}^{i}, \tau_{2}^{i}, s_{1}$ and $s_{2}$ and anticipating that we are only interested in symmetric equilibria so that $\tau_{t}^{i}=\tau_{t} \forall i=$ $1, \ldots, m_{1}, t=1,2$, we derive for the Hessian of the Lagrangian (27)

$$
H=\left(\begin{array}{cccc}
A_{11} & A_{12} & 0 & 0 \\
A_{21} & A_{22} & 0 & 0 \\
0 & 0 & A_{33} & 0 \\
0 & 0 & 0 & A_{44}
\end{array}\right)
$$

where

$$
\begin{aligned}
A_{11}= & \phi-2 \frac{m_{1}-1}{m_{1}} \eta+\frac{2\left(m_{1}-1\right) \eta \alpha_{1}}{m_{1}^{2}\left(\Theta_{1}-\bar{e}+\eta \tau_{1}\right)^{2}}\left\{\left(\Theta_{1}-\bar{e}+\eta \tau_{1}\right)^{2}\right. \\
& \left.+\eta f_{0}^{i}+\Theta_{1}\left(\bar{e}-\Theta_{1}\right)\right\} \\
A_{12}= & A_{21}=-\frac{\left(m_{1}-1\right)\left(1-\alpha_{1}\right) \alpha_{2} \eta\left(\bar{e}-2 \eta \tau_{1}\right)}{m_{1}^{2}\left(\Theta_{2}-\bar{e}+\eta \tau_{2}\right)}, \\
A_{22}= & \delta\left(\phi-2 \frac{m_{1}-1}{m_{1}} \eta\right)+\frac{2\left(m_{1}-1\right) \eta \alpha_{2}}{m_{1}^{2}\left(\Theta_{2}-\bar{e}+\eta \tau_{2}\right)^{2}}\left\{\delta\left(\Theta_{2}-\bar{e}+\eta \tau_{2}\right)^{2}\right. \\
& \left.+\eta\left(1-\alpha_{1}\right)\left[f_{0}^{i}+\tau_{1}\left(\bar{e}-\eta \tau_{1}\right)\right]+\delta \Theta_{2}\left(\bar{e}-\Theta_{2}\right)\right\}, \\
A_{33}= & \beta \\
A_{44}= & \delta \beta .
\end{aligned}
$$

The principal minors $M_{k}$ of $H$ are given by deleting all but the first $k$ lines and rows of $H$ :

$$
M_{1}=A_{11}, \quad M_{2}=\left(\begin{array}{cc}
A_{11} & A_{12} \\
A_{21} & A_{22}
\end{array}\right), \quad M_{3}=\left(\begin{array}{ccc}
A_{11} & A_{12} & 0 \\
A_{21} & A_{22} & 0 \\
0 & 0 & A_{33}
\end{array}\right), \quad M_{4}=H .
$$

A sufficient condition for $\operatorname{det}\left[M_{1}\right]=A_{11}>0$ is that the following condition holds:

$$
\phi \geq 2 \eta
$$

as all other terms in $A_{11}$ are strictly positive, at least in equilibrium. ${ }^{9}$ Furthermore, we see directly that $\operatorname{det}\left[M_{3}\right]$ and $\operatorname{det}\left[M_{4}\right]$ are strictly positive iff $\operatorname{det}\left[M_{2}\right]>0$ :

$$
\operatorname{det}\left[M_{3}\right]=A_{33} \operatorname{det}\left[M_{2}\right], \quad \operatorname{det}\left[M_{4}\right]=A_{33} A_{44} \operatorname{det}\left[M_{2}\right] .
$$

\footnotetext{
${ }^{9}$ Note that reasonable values for $\Theta_{t}$ are in the range $\left[\bar{e}-\eta \tau_{t}, \bar{e}\right]$, otherwise there would be no refunding and hence no additional incentive to abate.
} 
Defining the following abbreviations

$$
\begin{aligned}
B= & \phi-2 \frac{m_{1}-1}{m_{1}} \eta \\
C= & \frac{2\left(m_{1}-1\right) \eta \alpha_{1}}{m_{1}^{2}\left(\Theta_{1}-\bar{e}+\eta \tau_{1}\right)^{2}}\left\{\left(\Theta_{1}-\bar{e}+\eta \tau_{1}\right)^{2}+\eta f_{0}^{i}+\Theta_{1}\left(\bar{e}-\Theta_{1}\right)\right\} \\
D= & \frac{2\left(m_{1}-1\right) \eta \alpha_{2}}{m_{1}^{2}\left(\Theta_{2}-\bar{e}+\eta \tau_{2}\right)^{2}}\left\{\delta\left(\Theta_{2}-\bar{e}+\eta \tau_{2}\right)^{2}+\eta\left(1-\alpha_{1}\right)\left[f_{0}^{i}+\tau_{1}\left(\bar{e}-\eta \tau_{1}\right)\right]\right. \\
& \left.+\delta \Theta_{2}\left(\bar{e}-\Theta_{2}\right)\right\} \\
E= & \frac{\left(m_{1}-1\right)^{2}\left(1-\alpha_{1}\right)^{2} \alpha_{2}^{2} \eta^{2}\left(\bar{e}-2 \eta \tau_{1}\right)^{2}}{m_{1}^{4}\left(\Theta_{2}-\bar{e}+\eta \tau_{2}\right)^{2}}
\end{aligned}
$$

with $B, C, D, E>0$ (if $\phi-2 \eta>0$ holds), we can write $\operatorname{det}\left[M_{2}\right]$ as

$$
\begin{aligned}
\operatorname{det}\left[M_{2}\right] & =A_{11} A_{22}-A_{12}^{2} \\
& =\delta B^{2}+B(D+\delta C)+C D-E
\end{aligned}
$$

Obviously the following conditions hold:

$$
\frac{\partial B}{\partial f_{0}^{i}}=0, \quad \frac{\partial C}{\partial f_{0}^{i}}>0, \quad \frac{\partial D}{\partial f_{0}^{i}}>0, \quad \frac{\partial E}{\partial f_{0}^{i}}=0
$$

so for all values of $\phi, \eta, m_{1}, \bar{e}, \Theta_{1}, \Theta_{2}, \alpha_{1}, \alpha_{2}, \tau_{1}$, and $\tau_{2}$ there exists a lower bound $\underline{\mathrm{f}}$ such that for all $f_{0}^{i}>\underline{\mathrm{f}}$, $\operatorname{det}\left[M_{2}\right]>0$, and the Lagrangian (27) is strictly convex.

\section{Proof of Proposition 5}

According to Proposition 3 the CA's tax goal if $m_{1}$ countries participate in the GRS in both periods is given by equations (20) setting $m_{2}=m_{1}$. From equations (A.4) and (A.3a) we know that

$$
\eta \beta \sum_{k=t}^{2}[\delta(1-\gamma)]^{k-t} s_{k}=\frac{\phi \tau_{t}^{T G}}{m_{1}}, \quad t=1,2 .
$$

Inserting $\tau_{1}^{T G}, \tau_{2}^{T G}$ and equation (A.18) into equations (31), we derive the following system of equations:

$$
\begin{aligned}
\frac{m_{1}-1}{m_{1}} \phi \tau_{1}^{T G} & =\eta \alpha_{1} f_{1} \frac{\left(m_{1}-1\right)}{m_{1}^{2}\left(\Theta_{1}-\bar{e}+\eta \tau_{1}^{T G}\right)}-\left(\bar{e}-2 \eta \tau_{1}^{T G}\right) \frac{m_{1}-1}{m_{1}} \\
\frac{m_{1}-1}{m_{1}} \phi \tau_{2}^{T G} & =\eta \alpha_{2} f_{2} \frac{\left(m_{1}-1\right)}{m_{1}^{2}\left(\Theta_{2}-\bar{e}+\eta \tau_{2}^{T G}\right)}-\left(\bar{e}-2 \eta \tau_{2}^{T G}\right) \frac{m_{1}-1}{m_{1}} .
\end{aligned}
$$


Solving these equations for $\alpha_{1}$ and $\alpha_{2}$ and inserting the formulae (24) for $f_{1}$ and $f_{2}$ yields

$$
\begin{aligned}
\alpha_{1} & =\frac{\left[\bar{e}+\tau_{1}^{T G}(\phi-2 \eta)\right]\left(\Theta_{1}-\bar{e}+\eta \tau_{1}^{T G}\right)}{\eta\left[f_{0}^{i}+\tau_{1}^{T G}\left(\bar{e}-\eta \tau_{1}^{T G}\right)\right]}, \\
\alpha_{2} & =\frac{\left[\bar{e}+\tau_{2}^{T G}(\phi-2 \eta)\right]\left(\Theta_{2}-\bar{e}+\eta \tau_{2}^{T G}\right)}{\eta\left\{\frac{1-\alpha_{1}}{\delta}\left[f_{0}^{i}+\tau_{1}^{T G}\left(\bar{e}-\eta \tau_{1}^{T G}\right)\right]+\tau_{2}^{T G}\left(\bar{e}-\tau_{2}^{T G}\right)\right\}} .
\end{aligned}
$$

Obviously, $\alpha_{1}$ and $\alpha_{2}$ are non-negative for any reasonable choice of $\Theta_{t} \in\left[\bar{e}-\eta \tau_{t}^{\star}, \bar{e}\right]$ $(t=1,2)$ if condition (29) holds. Moreover, for any set of exogenously given parameters, any $\tau_{t}^{\star}$ and any given $f_{0}^{i}$, there is an interval of feasible $\Theta_{t} \in\left[\Theta_{t}^{\min }, \bar{e}\right]$ such that $\alpha_{t} \in[0,1]$. As a consequence, the CA can always find suitable GRS parameters o ensure that the tax goal $\tau_{1}^{T G}$ and $\tau_{2}^{T G}$ is supported as a Nash equilibrium of the individual countries' optimization problem.

\section{Proof of Corollary 2:}

Set $f_{0}^{i}$ such that the Lagrangian (27) is strictly convex (Proposition 4). According to Proposition 5 there exist feasible parameter values $\alpha_{t}, \Theta_{t}$ such that the global social optimum is a subgame perfect equilibrium. Due to the strict convexity of the Lagrangian for all countries $i \in G R S$ the subgame perfect equilibrium is unique.

\section{Proof of Proposition 6}

The Lagrangian for the optimization problem (34), subject to equations (3), (1), (24) and $\tau_{2}^{i} \geq 0$, reads:

$$
\begin{aligned}
\mathcal{L}= & \frac{\phi}{2}\left(\tau_{2}^{i}\right)^{2}+\frac{\beta}{2} s_{2}^{2}+\tau_{2}^{i}\left(\bar{e}-\eta \tau_{2}^{i}\right)-\alpha_{2} f_{2} \frac{\Theta_{2}-\bar{e}+\eta \tau_{2}^{i}}{\sum_{j=1}^{m_{2}}\left(\Theta_{2}-\bar{e}+\eta \tau_{2}^{j}\right)}-\frac{1-\alpha_{2}}{m_{2}} f_{2} \\
& +\lambda_{2}^{G R S}\left[(1-\gamma) s_{1}+\sum_{j=1}^{n}\left(\bar{e}-\eta \tau_{t}^{j}\right)-s_{2}\right] .
\end{aligned}
$$

Following the same line of argument as in Section 4.2, one derives the following necessary condition for all countries $i$ :

$$
\phi \tau_{2}=\eta \beta s_{2}+\frac{\left(m_{2}-1\right) \eta \alpha_{2} f_{2}}{m_{2}^{2}\left(\Theta_{2}-\bar{e}+\eta \tau_{2}\right)}-\left(\bar{e}-2 \eta \tau_{2}\right) \frac{m_{2}-1}{m_{2}} .
$$


Again, the CA seeks policy parameters $\alpha_{2}$ and $\Theta_{2}$ such that equation (A.22) holds when inserting the tax goal $\tau_{2}^{T G}$, as given by equation 33a. We know from equations (A.4) and (A.3a) that

$$
\eta \beta s_{2}=\frac{\phi \tau_{2}^{T G}}{m_{2}} .
$$

Inserting $\tau_{2}^{T G}, \tau_{2}^{T G}$, and equation (A.23) into equation (A.22), we derive

$$
\frac{m_{2}-1}{m_{2}} \phi \tau_{2}^{T G}=\eta \alpha_{2} f_{2} \frac{\left(m_{2}-1\right)}{m_{2}^{2}\left(\Theta_{2}-\bar{e}+\eta \tau_{2}^{T G}\right)}-\left(\bar{e}-2 \eta \tau_{2}^{T G}\right) \frac{m_{2}-1}{m_{2}} .
$$

Solving this equation for $\alpha_{2}$ and inserting the formulae (24) for $f_{1}$ and $f_{2}$ yields

$$
\alpha_{2}=\frac{m_{2}\left[\bar{e}+\tau_{2}^{T G}(\phi-2 \eta)\right]\left(\Theta_{2}-\bar{e}+\eta \tau_{2}^{T G}\right)}{\eta\left\{\frac{1-\alpha_{1}}{\delta} m_{1}\left[f_{0}^{i}+\tau_{1}^{T G}\left(\bar{e}-\eta \tau_{1}^{T G}\right)\right]+m_{2} \tau_{2}^{T G}\left(\bar{e}-\tau_{2}^{T G}\right)\right\}} .
$$

Analogously to equation (A.20b) in the proof of Proposition 5, the CA can always find suitable GRS parameters ensuring that tax goal $\tau_{2}^{T G}$ is supported as a Nash equilibrium of the individual countries' optimization problem.

\section{Proof of Proposition 7}

Given that $m_{1}-m_{2}$ countries do not participate in the GRS in period $t=2$ and minimize (32) subject to equations (3), (1), (33a), and $\tau_{2}^{j} \geq 0, j \notin G R S$, the Lagrangian reads

$$
\mathcal{L}=\frac{\phi}{2}\left(\tau_{2}^{j}\right)^{2}+\frac{\beta}{2} s_{2}^{2}+\lambda^{F}\left[(1-\gamma) s_{1}^{T G}+n \bar{e}-\eta\left(\sum_{j=m_{2}+1}^{n} \tau_{2}^{j}+m_{2} \tau_{2}^{G R S}\right)-s_{2}\right] .
$$

This leads to the following necessary and (due to the strict convexity of the Lagrangian) also sufficient condition for country $j$ :

$$
\phi \tau_{2}^{j}=\eta \beta\left[(1-\gamma) s_{1}^{T G}+n \bar{e}-\eta\left(\sum_{j=m_{2}+1}^{n} \tau_{2}^{j}+m_{2} \tau_{2}^{G R S}\right)\right] .
$$

Looking only for symmetric equilibria $\tau_{2}^{j}=\tau_{2}^{\text {GRS }}$ and supposing that the CA can implement tax goal $\tau_{2}^{T G}$, we derive the following set of linear equations:

$$
\begin{aligned}
\tau_{2}^{G R S} & =\eta \beta \frac{(1-\gamma) s_{1}^{T G}+n \bar{e}-\eta m_{2} \tau_{2}^{G R S}}{\phi+\left(n-m_{2}\right) \eta^{2} \beta} \\
\tau_{2}^{G R S} & =m_{2} \eta \beta \frac{(1-\gamma) s_{1}^{T G}+n \bar{e}-\eta\left(m_{1}-m_{2}\right) \tau_{2}^{G R S}}{\phi+m_{2}^{2} \eta^{2} \beta}
\end{aligned}
$$


the unique solution of which is given by equations (35). Inserting $\tau_{2}^{G R S}$ and $\tau_{2}^{G R S}$ into the equation of motion for the stock of greenhouse gases (3) yields equation (36)

\section{Proof of Proposition 8}

Inserting equations (35) and (36) into equations (37)-(39) yields for $\Delta C\left(m_{2}\right)$

$$
\begin{aligned}
\Delta C\left(m_{2}\right)= & \frac{\phi \beta}{2}\left[n \bar{e}+(1-\gamma) s_{1}^{T G}\right]^{2}\left\{\frac{\phi+\eta^{2} \beta m_{2}^{2}}{\left[\phi+\eta^{2} \beta\left(m_{1}-m_{2}+m_{2}^{2}\right)\right]^{2}}\right. \\
& \left.-\frac{\phi+\eta^{2} \beta}{\left[\phi+\eta^{2} \beta\left(2+m_{1}-3 m_{2}+m_{2}^{2}\right)\right]^{2}}\right\}-\frac{m_{1}\left(1-\alpha_{1}\right)}{m_{2} \delta}\left[f_{0}^{i}+\tau_{1}^{T G}\left(\bar{e}-\eta \tau_{1}^{T G}\right)\right] .
\end{aligned}
$$

While the first term is completely determined by exogenously given parameters and may be positive (in fact, it can be shown to be positive for $m_{2} \geq 3$ ), the second term is always negative and a linear function of $f_{0}^{i}$. Thus there exists an $\hat{f}_{0}^{i}$ such that $\Delta C\left(m_{2}\right)<0$ for all $m_{2}=1, \ldots, m_{1}$ if $f_{0}^{i}>\hat{f}_{0}^{i}$. 


\section{References}

Aldy, J., Barrett, S. And R. Stavins (2003): '13+1: a comparison of global climate change policy architectures'. Discussion-Paper No. 03-26, Resources for the Future, Washington, DC.

Andreoni, J. (1998): 'Toward a theory of charitable fund-raising', Journal of Political Economy, 106: 1186-213.

Asheim, G., Froyn, C.B., Hovi, J. And F. C. Menz (2006): 'Regional versus global cooperation for climate control', Journal of Environmental Economics and Management, 51: 93-109.

BARRETT, S. (1994): 'Self-inforcing international environmental agreements', Oxford Economic Papers, 46: 878-94.

BARRETt, S. (1999): 'A theory of full international cooperation', Journal of Theoretical Politics, 11: 519-41.

Barrett, S. (2003): Environment and Statecraft. Oxford University Press, Oxford.

Böhringer, C. And C. Vogt (2003): 'Economic and environmental impacts of the Kyoto protocol', Canadian Journal of Economics, 36: 475-94.

Carraro, C. (Ed.) (2000): Efficiency and Equity of Climate Change Policy. Kluwer, Dordrecht.

Carraro, C., Eyckmans, J. and M. Finus (2006): 'Optimal transfers and participation decisions in international environmental agreements', Review of International Organizations, 1: 379-96.

Carraro, C. And D. Siniscalco (1993): 'Strategies for the international protection of the environment', Journal of Public Economics, 52: 309-28.

Carraro, C. and D. Siniscalco (1998): 'International environmental agreements: incentives and political economy', European Economic Review, 42: 561-72.

Chander, P. And H. Tulkens (1992): 'Theoretical foundations of negotiations and cost sharing in transfrontier pollution problems', European Economic Review, 36: 388-99. 
FALK, I. AND R. MENDELSOHN (1993): 'The economics of controlling stock pollutants: An efficient strategy for greenhouse gases', Journal of Environmental Economics and Management, 25: 76-88.

Finus, M., van Ierland, E. And R. Dellink (2006): 'Stability of climate coalitions in a cartel formation game', Economics of Governance, 7: 271-91.

Gersbach, H. (2007): 'The global refunding system and climate change'. WorkingPaper No. 07/62, CER-ETH - Center of Economic Research at ETH Zurich.

Goulder, L. And W. Pizer (forthcoming): 'The economics of climate change'. In Durlauf, S. And L. Blume (Eds.): New Palgrave Dictionary of Economics. 2nd edition. Macmillan, Basingstoke.

Hoel, M. (1992): 'International environment conventions: The case of uniform reductions of emissions', Environmental and Resource Economics, 2: 141-59.

LAnge, A. (2006): 'Providing public goods in two steps', Economics Letters, 91: 17378.

McKibinin, W. And P. Wilcoxen (2002): 'The role of economics in climate change policy', Journal of Economic Perspectives, 16: 107-29.

Nordhaus, W.D. (2006): 'After Kyoto: alternative mechanisms to control global warming', American Economic Review, 96: 31-4.

Nordhaus, W. D. And J. G. Boyer (1999): 'Requiem for Kyoto: an economic analysis'. In: The Costs of the Kyoto Protocol: A Multi-Model Evaluation. Energy Journal, Special Issue. Pages 93-130.

Schelling, T. C. (2002): 'What makes greenhouse sense? Time to rethink the Kyoto protocol', Foreign Affairs, 81: 2-9.

Stern, N. (2006): The Economics of Climate Change - The Stern Review. Cambridge University Press, Cambridge.

ToL, R. (2006): 'Why worry about climate change? A research agenda'. Nota di Lavoro 136.2006, Fondazione Eni Enrico Mattei, Milano.

VARIAN, H. R. (1994): 'Sequential contributions to public goods', Journal of Public Economics, 53: 165-86. 


\section{Working Papers of the Center of Economic Research at ETH Zurich}

(PDF-files of the Working Papers can be downloaded at www.cer.ethz.ch/research).

07/69 H. Gersbach and R. Winkler

On the Design of Global Refunding and Climate Change

07/68 S. Valente

Human Capital, Resource Constraints and Intergenerational Fairness

07/67 O. Grimm and S. Ried

Macroeconomic Policy in a Heterogeneous Monetary Union

07/66 O. Grimm

Fiscal Discipline and Stability under Currency Board Systems

07/65 M. T. Schneider

Knowledge Codification and Endogenous Growth

07/64 T. Fahrenberger and H. Gersbach

Legislative Process with Open Rules

07/63 U. von Arx and A. Schäfer

The Influence of Pension Funds on Corporate Governance

07/62 H. Gersbach

The Global Refunding System and Climate Change

06/61 C. N. Brunnschweiler and E. H. Bulte

The Resource Curse Revisited and Revised: A Tale of Paradoxes and Red Herrings

06/60 R. Winkler

Now or Never: Environmental Protection under Hyperbolic Discounting

06/59 U. Brandt-Pollmann, R. Winkler, S. Sager, U. Moslener and J.P. Schlöder

Numerical Solution of Optimal Control Problems with Constant Control Delays

06/58 F. Mühe

Vote Buying and the Education of a Society

06/57 C. Bell and H. Gersbach

Growth and Enduring Epidemic Diseases

06/56 H. Gersbach and M. Müller

Elections, Contracts and Markets

06/55 S. Valente

Intergenerational Transfers, Lifetime Welfare and Resource Preservation

06/54 H. Fehr-Duda, M. Schürer and R. Schubert

What Determines the Shape of the Probability Weighting Function? 
06/53 S. Valente

Trade, Envy and Growth: International Status Seeking in a Two-Country World

06/52 K. Pittel

A Kuznets Curve for Recycling

06/51 C. N. Brunnschweiler

Cursing the blessings? Natural resource abundance, institutions, and economic growth

06/50 C. Di Maria and S. Valente

The Direction of Technical Change in Capital-Resource Economics

06/49 C. N. Brunnschweiler

Financing the alternative: renewable energy in developing and transition countries

06/48 S. Valente

Notes on Habit Formation and Socially Optimal Growth

06/47 L. Bretschger

Energy Prices, Growth, and the Channels in Between: Theory and Evidence

06/46 M. Schularick and T.M. Steger

Does Financial Integration Spur Economic Growth? New Evidence from the First Era of Financial Globalization

05/45 U. von Arx

Principle guided investing: The use of negative screens and its implications for green investors

05/44 Ch. Bjørnskov, A. Dreher and J.A.V. Fischer

The bigger the better? Evidence of the effect of government size on life satisfaction around the world

05/43 L. Bretschger

Taxes, Mobile Capital, and Economic Dynamics in a Globalising World

05/42 S. Smulders, L. Bretschger and H. Egli

Economic Growth and the Diffusion of Clean Technologies: Explaining Environmental Kuznets Curves

05/41 S. Valente

Tax Policy and Human Capital Formation with Public Investment in Education

05/40 T.M. Steger and L. Bretschger

Globalization, the Volatility of Intermediate Goods Prices and Economic Growth

05/39 H. Egli

A New Approach to Pollution Modelling in Models of the Environmental Kuznets Curve

05/38 S. Valente

Genuine Dissaving and Optimal Growth 
05/37 K. Pittel, J.-P. Amigues and T. Kuhn, Endogenous Growth and Recycling: A Material Balance Approach

05/36 L. Bretschger and K. Pittel

Innovative investments, natural resources, and intergenerational fairness: Are pension funds good for sustainable development?

04/35 T. Trimborn, K.-J. Koch and T.M. Steger

Multi-Dimensional Transitional Dynamics: A Simple Numerical Procedure

04/34 K. Pittel and D.T.G. Rübbelke

Private Provision of Public Goods: Incentives for Donations

04/33 H. Egli and T.M. Steger

A Simple Dynamic Model of the Environmental Kuznets Curve

04/32 L. Bretschger and T.M. Steger

The Dynamics of Economic Integration: Theory and Policy

04/31 H. Fehr-Duda, M. de Gennaro, R. Schubert

Gender, Financial Risk, and Probability Weights

03/30 T.M. Steger

Economic Growth and Sectoral Change under Resource Reallocation Costs

03/29 L. Bretschger

Natural resource scarcity and long-run development: central mechanisms when conditions are seemingly unfavourable

03/28 H. Egli

The Environmental Kuznets Curve - Evidence from Time Series Data for Germany

03/27 L. Bretschger

Economics of technological change and the natural environment: how effective are innovations as a remedy for resource scarcity?

03/26 L. Bretschger, S. Smulders

Sustainability and substitution of exhaustible natural resources. How resource prices affect long-term R\&D-investments

03/25 T.M. Steger

On the Mechanics of Economic Convergence

03/24 L. Bretschger

Growth in a Globalised Economy: The Effects of Capital Taxes and Tax Competition

02/23 M. Gysler, J.Kruse and R. Schubert

Ambiguity and Gender Differences in Financial Decision Making: An Experimental Examination of Competence and Confidence Effects 